\title{
OBSERVED PRECIPITATION TREND CHANGES IN THE WESTERN
}

\section{MEDITERRANEAN REGION}

(1)

(1)

Javier Valdes-Abellan ${ }^{\mathrm{a},}$, M.A. Pardo ${ }^{\mathrm{b}}$, A.J. Tenza-Abril ${ }^{\mathrm{b}}$,

a Department of Civil Engineering, University of Alicante, Alicante, Spain.javier.valdes@ua.es

${ }^{b}$ Department of Civil Engineering, University of Alicante, Alicante, Spain.

\section{ABSTRACT}

This paper analyses the daily precipitation data recorded for the last 75-80 years in SE Spain. Prior to statistical analysis, homogeneity tests were performed to determine the usefulness of the data (recorded in 6 pluviometric stations). If the data were homogeneous, the MannKendall test was performed to detect monotonic trends for variables such as total precipitation, number of days with precipitation greater than 1, 20 or $40 \mathrm{~mm}$, number of consecutive dry days and number of consecutive wet days. Moreover, the linear tendency was calculated and accepted (or rejected) by performing a Student's t test of the calculated residual values.

The results showed, on average, a clear change in precipitation patterns for the last 20 years. Annual rainfall had decreased, with values ranging from 0 to $15 \%$, dry periods had increased in length, and the number of rainy days had decreased (especially when high daily precipitation was considered). This latter notion did not exactly concur with the conclusions of the IPCC 2014 Synthesis Report related to the study area.

\section{KEYWORDS}

Drought, semiarid regions, breakpoints, rainfall reduction, daily precipitation patterns. 


\section{INTRODUCTION}

Climate change and its impact on society and the environment are primary areas of focus worldwide and are becoming even more important due to the increased observation of extreme events. Most significant meteorological events depend on the region and the exposure and vulnerability of each specific society/environment with regards to its climate.

In arid and semiarid regions, conventional water resources are insufficient for meeting all water demand, even after considering wastewater reuse and desalination (Molina and Melgarejo, 2015), leading to strong competition among users (MedWSD Working Group, 2008). In these regions, the rigorous study of climate change and the detection of temporal trends in precipitation are fundamental, even more so if we consider that their development could be constrained by water resource limitations (Lattemann and Höpner, 2008).

The Intergovernmental Panel on Climate Change, IPCC, states in its periodical reports (IPCC, 2014; IPCC, 2007) that there is a high probability (9 out of 10) that by mid-century, annual river runoff and water availability will decrease in some dry regions. Specifically, the IPCC states that the Mediterranean Basin, among others, will suffer a decrease in water resources. Additionally, Mediterranean-type ecosystems and agriculture at low latitudes are likely (>66\% probability) to be directly affected by climate change because of a reduction in rainfall and water availability. Simultaneously, these same reports state that it is very likely ( $>90 \%$ probability) that the frequency of heavy precipitation will increase over most areas around the globe.

However, the IPPC has highlighted that changes in extreme episodes will be more difficult

to analyse and that it will be more difficult to derive general trends and changes because of higher spatial and seasonal variability. An analysis of these extremes requires data series from longer periods and with higher spatial and temporal resolutions. 
Therefore, from the point of view of the Mediterranean Region and considering the 50 projection of drier conditions, addressing studies on climate trends has become an important 51 challenge (Hatzianastassiou et al., 2016). This region belongs to a water-stressed country (EEA, 52 2005) with one of the highest water exploitation indices (the result of considering total water 53 abstraction per year as a percentage of long-term freshwater resources in 1990 and 2002) in 54 Europe. Moreover, water-stressed regions will grow in all Mediterranean countries in the future. The impacts of climate and its potential changes in the region have been analysed from different perspectives as follows: soils and their climate-dependent behaviours (Boix et al., 1995); the impacts of climate on the tourism industry (Ibarra, 2011); aquifer recharge (Aguilera and Murillo, 2009; Touhami et al., 2015); and the prediction of climate change by using complex numerical models and climate change scenarios (Monjo et al., 2015). Some previous studies have focused on the temporal trends of observed values in the Iberian Peninsula (Rodrigo and Trigo, 61 2007) but used short data series, analysed annual values with their natural randomness (instead 62 of 31-year averages) and did not consider the possible presence of linear trends and breakpoints 63 in the temporal series. Moreover, in their paper, Rodrigo and Trigo (2007) did not observe a 64 reduction in the number of wet days, and their analysis did not discriminate between different 65 thresholds of daily precipitation. This distinction is in fact very relevant (García et al., 2007; 66 Norrant and Douguédroit, 2006), as it will be shown later. Other studies in Spain have revealed 67 that the probability of extreme wet conditions has not increased (Rodrigo, 2010) but have not

68 suggested any conclusive negative trends. The analysis of annual and random values instead of 69 long-period averages may be one reason for this lack of significance. Nevertheless, studies carried 70 out in central and northern Europe have indicated a shift towards more frequent events of strong 71 precipitation (Frei et al., 1998; Łupikasza et al., 2011). 
The present study filled this gap and analysed the observed climate data from the most representative meteorological stations in this area (UTM30S coordinates are included): Alicante (718904; 4250120), Valencia (726514; 4373419), Librilla (644098; 4194576), Murcia (655618; 4202611), Orihuela $(79745 ; 4216860)$ and Pinoso $(671237 ; 4252574)$. The study focused on precipitation, both of extreme events and average annual indicators, since changes in any of these would imply a significant impact on water resources and, subsequently, on societal development and the regional environment.

\section{MATERIAL AND METHODS}

\subsection{Site study and social/economical context}

The study area was located in SE Spain as well as the western Mediterranean Sea (Figure 1). The area is a coastal plain in the eastern part of the External Zone of the Betic range called the Prebetic domain (Alfaro et al., 2004; IGME, 1963). The most important reliefs, lying primarily in an SW-NE direction, correspond to cretaceous limestone and marls, and the elevation ranges from sea level to $1200-1400 \mathrm{~m}$ over a distance of less than $20 \mathrm{~km}$.

This region is characterised by a semi-arid Mediterranean climate with an average annual temperature of $18^{\circ} \mathrm{C}$, a low annual precipitation rate of $290-460 \mathrm{~mm} \cdot \mathrm{yr}^{-1}$, dry and hot summers and mild winters. Additionally, the majority of rainfall occurs in autumn, which is when intense rainfall events can occur. The climate and precipitation regimes are mainly controlled by thermally driven flows on heated slopes of low steepness that may couple with sea breezes, increasing horizontal and vertical wind speeds and creating an earlier inland sea breeze frontal passage (Azorin-Molina et al., 2011). In contrast, a heated slope of high steepness blocks the inland propagation of sea breezes and decreases horizontal and vertical wind speeds (Crosman and Horel, 2010). 
Valencia, Alicante and Murcia Provinces are the third, fifth and tenth most populated regions in Spain, with 2.58, 1.90 and 1.46 million inhabitants, respectively, (National Statistics Institute; www.ine.es). Groundwater is the most significant and strategic source of fresh water in the region, especially in Alicante Province. The water supply for Murcia Province relies on external inflows from other watersheds, and Valencia Province is the only area with significant surface water resources. In the last few years, desalination of seawater and brackish aquifer water has become a very important method for obtaining water to complement traditional and scarce water resources. Nevertheless, the area suffers from a structural water shortage and requires the transfer of water from other basins to meet all water needs (Molina and Melgarejo, 2015).

\subsection{Climate data}

Daily precipitation data were provided by the National Meteorological Agency, AEMET, which is in charge of the stations' maintenance and provides a wide range of meteorological information. Every station selected had the longest temporal series of precipitation in the area (from the early 1940s to present day, with no gaps in some cases), so the precipitation data analysed in this study varied between 75 and 82 years (additional information about length, gaps and altitude is included in Figure 1).

Prior to the statistical analysis itself, the methodology explained by Wijngaard et al. (2003) was applied to the annual precipitation temporal series to detect inhomogeneities in precipitation data. This methodology included the following four tests: SNHT for a single break (Alexandersson, 1986), Buishand range test (Buishand, 1982), Pettitt test (Pettitt, 1979) and von Neumann ratio test (von Neumann, 1941). Wijngaard classified the data as 'useful' (zero or one test rejection based on the null hypothesis of the homogeneous series at the $1 \%$ level), 'doubtful' (two rejections) and 'suspect' (three or four rejections). In addition to these tests to check 
homogeneity, piecewise linear fitting methodology was applied in this study (Tomé and Miranda, 2004) to quantify trends and report breakpoints in temporal trends.

\subsection{Statistical analysis}

Once the time series were accepted, the first step in the analysis was to obtain annual values of a number of parameters included in Table 1. In addition to these annual indices and because of their natural randomness, moving averages across 31 years were computed following standard procedures in climatic research (Martin Vide, 2003). The results for these averages were assigned to the last year of the period considered (i.e., value of the 31-year moving average of 2016 corresponded to the 1986-2016 period). The following analyses were based on the moving averages (not on annual values) to reduce randomness and to identify stronger trends, if any.

The presence of temporal trends in the average series and their statistical significance were verified by the non-parametric Mann-Kendall test (Helsel and Hirsch, 2002; Mann, 1945) at a significance level of $p=0.05$. This test detects the presence of monotonic trends. If the variable $x$ is time, the null hypothesis, $\mathrm{H}_{0}$, means no temporal trends and assumes that increasing or decreasing observations can be randomly observed along the temporal series.

$$
\text { In the Mann-Kendall test, the two following values are calculated: }
$$
the monotonic relationship, which depends only on the ranks of the data and ranges from -1 to 1 (the closer to \pm 1 , the stronger correlation); the second value is $\mathrm{Zs}$, which is the cumulative probability for a standard normal distribution if $\mathrm{H}_{0}$ is true. $\mathrm{Zs}$ is compared with $\mathrm{Z}_{\text {crit }}$ (the value of the standard normal distribution with a probability of exceeding If $|\mathrm{Zs}|<\mathrm{Z}_{\text {crit }}$, the null hypothesis cannot be rejected, and the words "No trends" were included in table 3. If not, temporal trends do exist, and then two values are released with regard to every station and variable computed. 
If $\mathrm{H}_{0}$ was rejected, the trends were quantified by the application of piecewise linear fitting explained by Tome and Miranda (2004). This methodology was applied to determine the presence and location of potential breakpoints in the temporal series since we believed that partial trends with periods shorter than the complete study period could exist. The breakpoint position was defined as the location that minimises the RMSE of all possible combinations of two line segments and constrained to have their endpoints intersecting at the year of change point (i.e., the breakpoint position). The breakpoint location was optimised by meeting a new condition: the length between breakpoints had to be at least 15 years, as highlighted by similar cases such as the NAO index (Walker, 1924; Ostermeier and Wallace 2003). The proposed algorithm finds the two linear adjustments with the following equations:

$$
\begin{array}{ll}
\mathrm{y}_{1}=\mathrm{a}_{1} \cdot \mathrm{t}+\mathrm{c}_{1} & \mathrm{i}=1,2, \ldots ., \mathrm{BP} \\
\mathrm{y}_{2}=\mathrm{a}_{2} \cdot \mathrm{t}+\mathrm{c}_{2} & \mathrm{i}=\mathrm{BP}+1, \mathrm{BP}+2, \ldots ., \mathrm{m}
\end{array}
$$

where BP was the breakpoint year, and $\mathrm{m}$ was the last year of the series.

The minimisation of RMSE was accomplished by using the fminsearch function in Matlab software ${ }^{\circledast}$ by changing $a_{1}, a_{2}$ and $c_{1}$ parameters $\left(c_{2}\right.$ was obtained as a function of the previous three after considering an additional condition: both linear trends had to have the same value in the breakpoint location). The algorithm is based on the simplex search method developed by Lagarias et al. (1998), which was corrected to avoid minimum local results.

Changes in daily precipitation patterns were also analysed. Considering precipitation from wet days (i.e., excluding zeros), the probability distribution functions (pdf) were fitted to the observed values. Several pdfs were considered (gamma, lognormal, extreme values, exponential), and the Kolmogorov-Smirnov test, KS, was applied to the results with the best fit before their acceptance. Finally, the function that reported the lowest RMSE was accepted. The temporal 
167 trends of the parameters from the pdf with the best fits were analysed, and if the trend was 168 statistically significant, the linear trend was determined.

169 Then, a two-by-two comparison between 31-year samples was performed (1081 170 combinations from 47 different 31-year periods) in order to find differences using the Student's $t$ 171 test for averages and the F-Snedecor test for standard deviations (Helsel and Hirsch, 2002). This 172 stage was applied to the pdf parameters of rainy day precipitation patterns (e.g., if comparisons 173 between the years 1970 and 2010 yielded a rejection of $\mathrm{H}_{0}$, this meant that daily precipitation in 174 the 1940-1970 period was significantly different from the daily precipitation in the 1980-2010 175 period).

176 Later, the residual values were analysed to trust the model obtained. A one-sample t-test 177 was applied to check the Gaussian distribution of errors (Table S8 of the Supplementary 178 Materials). Finally, the confidence intervals for the true population means, returned as a two179 element vector containing the lower and upper boundaries of the 95\% confidence interval, are 180 also depicted in Table S8 (row 5 and 6 for each variable and station analysed).

181 Finally, in order to obtain comparable results between the analysed stations, the absolute 182 results were divided by the total series average.

\section{RESULTS AND DISCUSSION}

\subsection{Homogeneity tests}

The results obtained from the homogeneity tests classified the precipitation time series as

188 'useful' for our objectives (Table 2) for all of the stations. The critical values, which depend on the 189 length of the data series analysed, are shown in the second column of every station in Table 2; 190 and in three of the four tests (all but the von Neumann test), the year in which the tendency was 
191 likely to change (third column shown) according to each individual test is shown. Based on the 192 results and following Wijngaard (2003), no correction procedures were required, and the 193 statistical analyses were applied directly to the observed series. It is worthwhile to note that 194 applying the Wijngaard methodology to the number of wet days, more specifically DP-1, indicated 195 that the PINOSO station should have been classified as 'suspect' because three of the four tests 196 rejected the null hypothesis. Nevertheless, we did not remove this station because the results did

197 198 199 200 201 202

\subsection{Annual precipitation amounts}

Figure 2 presents the results from the annual precipitation analysis, but linear tendencies were not depicted if the linear trends were not statistically significant. With the exception of Valencia, all temporal series of the moving averages showed slightly decreasing trends in the first 20 years, which collected information from the first 51 years because of the 31-year averages. Later, the decreasing trend intensified during the last decades with reductions of up to $15.6 \%$ in total annual precipitation in the case of the Alicante station. It was remarkable that the Valencia station's (located in the north with important mountain ranges between the other stations, Figure 1) moving average showed no variation, as predicted in Table 3 and highlighted in Figure 2. The correct values were as follows: Alicante, -15.6\%; Librilla, -6.75\%; Murcia, -6.22\%; Orihuela, 6.39\% and Pinoso, $-5.6 \%$.

\subsection{Number of rainy days}


The number of rainy days and their moving averages were computed considering different

thresholds (1, 20 and $40 \mathrm{~mm}$, Table 1). The lowest threshold of $1 \mathrm{~mm}$ (instead of 0 ) was based on Boccorali (2013) and/or Wijngaard (2003) because it was believed that this limit reduced the variability from year to year and caused less inhomogeneities to appear due to avoiding errors caused by measuring very low amounts (including dew) of precipitation. The results are depicted in Figure 3a and Figure 3b. A general reduction trend could be stated, especially for very wet days (>40 mm/day), with reductions in 5 of the 6 stations (Figure 3), which meant that the torrentiality of the rain decreased substantially. Similarly, in relation to total annual precipitation, the Valencia station demonstrated different behaviour compared to the other stations, showing an increasing trend for rainy days based on the three considered thresholds. When all of the rainy days were considered (even those with rainfall below $1 \mathrm{~mm}$ ), no significant reduction in the number of wet days was inferred, as this only affected three of the stations (Alicante, Murcia and threshold considered, the more important the changes were, regardless of the increasing (case of Valencia) or decreasing (other stations) trends.

\subsection{Length of rainy and dry periods}

Consecutive wet (i.e., DP-1) and dry days were summed in groups of 31 years (Martin Vide, 2003), and the average length of wet and dry periods was obtained for each group. A 'dry period' started with one day with no rain and continued until a day with precipitation equal to or higher than $1 \mathrm{~mm}$ appeared. At that moment, the 'dry period' ended, and a new 'wet period' began. The trends were statistically significant $(p=0.05)$ according to the Mann-Kendall test (Table 3). The results showed that the length of the wet periods increased in five of the six stations (Figure 4). However, the length of the dry periods increased in 2 of the stations (Alicante and 
Librilla; Figure 5). In other words, the changes at the Valencia station showed no trends according to the Mann-Kendall test (Table 3). Both of the increases in the length of dry and wet periods could be explained if we considered that the rotation between those periods was less common at that time.

Considering the fact that the length of both wet and dry periods remained constant or increased, the number of rainy days remained constant (in the case of very low thresholds) or decreased (in the case of high thresholds), and the annual precipitation decreased, we concluded that atmospheric periods with dry conditions were becoming more stable, and that atmospheric wet periods were longer with lower precipitation events.

\subsection{Precipitation in rainy days}

Among the considered pdfs, the lognormal function resulted in the best fit (among all of the functions that passed the KS test); complete information about the statistical results can be found in tables S1 to S6 in the Supplementary Materials section. Nevertheless, none of the considered pdfs passed the KS test for all three weather stations located outside Alicante Province. For the stations in Alicante Province, the temporal evolution of the mean value from the adjusted lognormal pdf showed a clear decrease in the three stations. In addition, the breakpoints were in the late eighties in all three, showing a change in the daily precipitation patterns in the region. The standard deviation also decreased in Alicante but not in Pinoso and Orihuela (Figure 6). These changes implied that daily rainfall was moving to lower values and that the probability of high daily precipitation values was decreasing, which was in agreement with the aforementioned reduction in the number of days with precipitation higher than $40 \mathrm{~mm}$.

The comparisons of the mean (Figure 7) and standard deviations indicated clear significant changes $(p=0.05)$ in both the statistics and results, which indicated consistent periods of time 
262 when significant differences existed between them. It is worthwhile to highlight the case of

263 Pinoso, where significant differences appeared after very few years, showing a quicker pace of 264 climate change. In the case of the fitted standard deviation, significant differences also appeared 265 but were limited to a few comparison periods.

266

267

268

269

270

\subsection{Temporal trends identification}

After analysing the different results obtained, a clear trend could be highlighted. Three of the four tests applied to check the homogeneity were known as location-specific tests, (i.e., they were capable of pinpointing the year where a break was likely to occur). Nevertheless, these results presented some biases that differentiated one from the other: the SNHT tended to detect breaks near the beginning and end of a series relatively easy, whereas the Buishand and Pettitt tests were more sensitive to breaks in the middle of a series. All of these tests were in agreement and pointed to the $1959-1989$ period in Alicante as the time when the climate changed. At other stations, the results were not as conclusive, or the breakpoints were not in agreement as much; however, at the Librilla, Murcia and Orihuela stations, the breakpoints moved to approximately 1955 and 1990 for indices such as total precipitation, DP-20 or DP-40.

From that moment to the present, on average, the climate has changed to drier conditions but with different rates for different stations. At the southern stations (Murcia, Librilla and Orihuela), the drying rates have diminished, but in Alicante and Valencia, the drying rates have increased with a clear reduction in total precipitation. Further studies are required to identify, if any, the causes of this evolving trend and if they are natural or anthropogenic.

The Pinoso stations showed a slightly different pattern, with increases in the total annual precipitation or DP-20 during the last twenty years, which may have been caused by their greater distance from the coastal plain area and the presence of relatively high mountains (900-1000 m 
altitude) between them. Additionally, all of the results from Pinoso should be considered with caution because the homogeneity test applied to the number of wet days considered the stations to be 'suspect'.

\section{CONCLUSIONS}

This study analysed the temporal evolution of several meteorological indices related with precipitation obtained from 31-year averages. The study used meteorological data from six meteorological stations located in the SE part of the Iberian Peninsula.

A clear change in tendency was observed from the period including the late fifties to the mid-nineties to the present. This new tendency pointed to drier conditions in accordance with some studies (Bladé and Castro Díez, 2010; García et al., 2007) but with different rates according to the location: the drying pace was slower in the southern stations and faster in the stations facing the eastern Mediterranean coast of the Iberian Peninsula. These previous works revealed a decrease in average precipitation equal to $-0.15 \mathrm{~mm} /$ day/decade in the period $2000-2008$. The data analysed here revealed a clear representative rainfall reduction in the western Mediterranean region, which has also been shown in some other papers (EEA, 2005; Rodrigo 2010) but not in the case of Bladé and Castro Díez (2010).

The results from the present study clearly show how different climate change can be among different locations, even with short distances between them, highlighting the importance of a dense observation network and further analysis of climatic trends even in the same 'apparent' region. Nevertheless, there was general agreement among stations and indices considering the same period as the breakpoint. The determination of factors that may have caused this change is an important issue that needs to be addressed in further studies. 
The results require serious consideration from water policymakers because in some areas

310 (such as Alicante, with a very low annual rainfall rate, $\sim 330 \mathrm{~mm}$ and almost 2 million inhabitants),

311 the climate is becoming even drier: the 31-year average of total annual precipitation decreased by

312 up to $15 \%$ in the last three decades; the number of wet days above $1 \mathrm{~mm}$ of precipitation slightly

313 decreased. However, the reductions were much more important with higher thresholds (above 40 $314 \mathrm{~mm}$; almost 40\% In Librilla; 40\% in Pinoso; 40\% in Alicante; $20 \%$ in Orihuela and 15\% in Murcia).

315 Based on these results, it was concluded that the higher the considered threshold is, the more 316 important the change is. Although the climate at Valencia station also became drier, it was not as 317 dry as the other stations (in fact, it was the station with the highest annual rainfall, $460 \mathrm{~mm}$ ).

318 The temporal evolution of the parameters that produced the best fitted lognormal pdf to 319 daily precipitation showed a reduction in the average, so the probability of high precipitation 320 events decreased.

321 The results only partially agreed with the expected climate change predictions reported by 322 the IPCC because the climate in the area had become drier in all aspects, not only the average 323 values but also the decreased frequency of heavy precipitation events.

All of these conclusions could have a significant negative impact on aquifer recharge (the main water resource in the region), mainly because of the reduction in the number of very wet days when recharge was mostly concentrated. We have not concluded that the observed trends in the recent past will continue in the future; nevertheless, it is clear that if these trends continue in the future, they will lead us to a very concerning scenario that water managers must consider. 329 The supply to meet all water needs will become more challenging in the following years, and its 330 economic impact in the region could be very important, especially for agriculture. However, 331 further studies need to be developed to confirm this notion. 


\section{ACKNOWLEDGEMENTS}

This study was partially financed by the CGL2013-48802-C3-3-R project (Spanish Ministry of Science and Innovation) and by the GRE15-19 (University of Alicante). Original data was provided by AEMET. We would like to acknowledge Aide Robles (North Arizona University) for the English revisions.

\section{REFERENCES}

Aguilera, H. and J.M. Murillo. 2009. The effect of possible climate change on natural groundwater recharge based on a simple model: A study of four karstic aquifers in SE Spain. Environ. Geol. 57: 963-974.

Alexandersson, H. 1986. A homogeneity test applied to precipitation data. Journal of Climatology 6: 661-675.

Alfaro, P., J.M. Andreu, A. Estévez, J.E. Tent-Manclús and Y. A. 2004. Geología de Alicante. AEPECT Universidad de alicante, Alicante.

Azorin-Molina, C., S. Tijm and D. Chen. 2011. Development of selection algorithms and databases for sea breeze studies. Theor. Appl. Climatol. 106: 531-546.

Bladé I. and Castro Díez Y., 2010. Atmospheric trends in the Iberian Peninsula during the instrumental period in the context of natural variability. Report: Climate in Spain:Past, Present and Future (Editors: Pérez F. Fiz and Boscolo Roberta) pp. 25-41.

Boccolari, M. and S. Malmusi. 2013. Changes in temperature and precipitation extremes observed in Modena, Italy. Atmos. Res. 122: 16-31.

Boix, C., A. Calvo, A. Cerdá, A.C. Imeson, M.D. Soriano and I.R. Tiemessen. 1995. Vulnerability of Mediterranean ecosystems to Climatic Change, study of soil degradation under different climatological conditions in an altitudinal transect in the south east of Spain. Stud Environ Sci 65: 763-766.

Buishand, T.A. 1982. Some methods for testing the homogeneity of rainfall records. J. Hydrol. 58: 11-27.

Crosman, E.T. and J.D. Horel. 2010. Sea and Lake Breezes: A Review of Numerical Studies. Boundary-Layer Meteorol. 137: 1-29.

European Environmental Agency (EEA, 2005), http://www.eea.europa.eu/themes/water/featured-articles/water-scarcity

Frei C., Schöll R, Fukutome S., Schmidli, J., Vidale Pl 2006. Future change of precipitation extremes in Europe: intercomparison of scenarios from regional climate models. Journal of Geophysical research 111: D06105 
García, J., Gallego, M. C., Serrano, A., and Vaquero, J.M., 2007. Trends in Block-Seasonal Extreme Rainfall over the Iberian Peninsula in the Second Half of the Twentieth Century. J. Climate, 20, 113-130.

Hatzianastassiou, N., C.D. Papadimas, C.J. Lolis, A. Bartzokas, V. Levizzani, J.D. Pnevmatikos, et al. 2016. Spatial and temporal variability of precipitation over the Mediterranean Basin based on 32-year satellite Global Precipitation Climatology Project data, part I: evaluation and climatological patterns. Int. J. Climatol.: n/a-n/a.

Helsel, D.R. and R.M. Hirsch. 2002. Statistical Methods in Water Resources Techniques of Water Resources Investigations, Book 4, chapter A3. U.S. Geological Survey.

Ibarra, E.M. 2011. The use of webcam images to determine tourist-climate aptitude: Favourable weather types for sun and beach tourism on the Alicante coast (Spain). Int. J. Biometeorol. 55: 373-385.

IGME. 1963. Mapa geológico de España. Alicante nº872. Servicio de Publicaciones, Ministerio de Industria C.S.G., Madrid.

IPCC, T.I.P.o.C.C. 2014. Climate Change 2014: Synthesis Report. Geneva (Switzerland).

IPCC, T.I.P.o.C.C. 2007. Climate Change 2007: Synthesis Report. Geneva (Switzerland).

Lagarias, J.C., Reeds, J.A., Wright, M.H., Wright, P.E., 1998. Convergence properties of the NelderMead simplex method in low dimensions. SIAM Journal on Optimization, 9(1): 112-147.

Lattemann, S. and T. Höpner. 2008. Environmental impact and impact assessment of seawater desalination. Desalination 220: 1-15.

Łupikasza, E.B., Hänsel, S., Matschullat, J., 2011. Regional and seasonal variability of extreme precipitation trends in southern Poland and central-eastern Germany 1951-2006. Int. J. Climatol., 31(15): 2249-2271. DOI:10.1002/joc.222

Mann, H.B. 1945. Nonparametric Tests Against Trend. Econometrica 13: 245-259.

Martin Vide, J. 2003. El tiempo y el clima. Ed. Rubes, Barcelona (Spain).

MedWSD Working Group. 2008. Mediterranean Water Scarcity and Drought Report. European Commission. Euro-Mediterranean Information System on know-how in the Water sector.

Molina, A. and J. Melgarejo. 2015. Water policy in Spain: seeking a balance between transfers, desalination and wastewater reuse. Int. J. Water Resour. Dev.

Monjo, R., E. Gaitán, J. Pórtoles, J. Ribalaygua and L. Torres. 2015. Changes in extreme precipitation over Spain using statistical downscaling of CMIP5 projections. Int. J. Climatol.

Norrant, C. and Douguédroit, A. (2006), Monthly and daily precipitation trends in the Mediterranean (1950-2000). Theor. Appl. Climatol. 83, 89-106 (2006)

Ostermeier, G. M., and J. M. Wallace (2003), Trends in the North Atlantic Oscillation-Northern Hemisphere Annular Mode during the Twentieth Century, J. Clim., 16, 336 - 341.

Pettitt, A.N. 1979. A Non-Parametric Approach to the Change-Point Problem. Journal of the Royal Statistical Society. Series C (Applied Statistics) 28: 126-135.

Rodrigo, F.S., Trigo, R.M., 2007. Trends in daily rainfall in the Iberian Peninsula from 1951 to 2002. Int. J. Climatol., 27(4): 513-529. DOI:10.1002/joc.1409 
Rodrigo, F.S., 2010. Changes in the probability of extreme daily precipitation observed from 1951 to 2002 in the Iberian Peninsula. Int. J. Climatol., 30(10): 1512-1525. DOI:10.1002/joc.1987

Tomé, A.R. and P.M.A. Miranda. 2004. Piecewise linear fitting and trend changing points of climate parameters. Geophys. Res. Lett. 31: L02207 02201-02204.

Touhami, I., E. Chirino, J.M. Andreu, J.R. Sánchez, H. Moutahir and J. Bellot. 2015. Assessment of climate change impacts on soil water balance and aquifer recharge in a semiarid region in south east Spain. J. Hydrol. 527: 619-629.

von Neumann, J. 1941. Distribution of the Ratio of the Mean Square Successive Difference to the Variance. 367-395.

Wijngaard, J.B., A.M.G. Klein Tank and G.P. Können. 2003. Homogeneity of 20th century European daily temperature and precipitation series. Int. J. Climatol. 23: 679-692.

Walker, G. T. (1924), Correlations in seasonal variations of weather IX, Mem. Ind. Meteorol. Dept., $24,275-332$.

\section{LIST OF FIGURES}

Figure 1. Study area and location of meteorological stations.

Figure 2. Annual precipitation depicted as single values and relative 31-year moving averages.

Figure 3. Daily precipitation averages for annual number of wet days above different thresholds.

Figure 4. Temporal evolution of average length of rainy periods.

Figure 5. Temporal evolution of average length of dry periods.

Figure 6. Temporal variation of lognormal averages and standard deviations for daily precipitation.

Figure 7. Significant differences in the average values fitted to daily precipitation. 
8. LIST OF TABLES

433 Table 1. Statistical indices obtained annually

\begin{tabular}{|c|c|}
\hline Description & Definition (units) \\
\hline Total precipitation & Total precipitation $(\mathrm{mm})$ \\
\hline DP & Number of days with observed precipitation (days) \\
\hline$D P-1$ & Number of days with $D P \geq 1 \mathrm{~mm}$ (days) \\
\hline DP-20 & Number of days with $D P \geq 20 \mathrm{~mm}$ (days) \\
\hline DP-40 & Number of days with $D P \geq 40 \mathrm{~mm}$ (days) \\
\hline W-Pe & Number of days of wet periods \\
\hline$D-P e$ & Number of days of dry periods \\
\hline$T P-w$ & Total precipitation in winter $(\mathrm{mm})$ \\
\hline TP-sp & Total precipitation in spring $(\mathrm{mm})$ \\
\hline TP-su & Total precipitation in summer $(\mathrm{mm})$ \\
\hline$T P-a u$ & Total precipitation in autumn $(\mathrm{mm})$ \\
\hline
\end{tabular}

Symbol DP denotes daily precipitation

434

435 Table 2. Values obtained at the Homogeneity test for the annual total precipitation in different stations

\begin{tabular}{|c|c|c|c|c|c|c|c|c|c|c|c|}
\hline \multirow[t]{2}{*}{ Station } & \multicolumn{3}{|c|}{ SNHT } & \multicolumn{3}{|c|}{ Buishand } & \multicolumn{3}{|c|}{ Pettit } & \multicolumn{2}{|c|}{ Von Neuman } \\
\hline & test & critical & year & test & critical & year & test & critical & year & test & critical \\
\hline Alicante & 2.60 & 11.99 & 1989 & 0.53 & 1.82 & 1989 & $596.00^{*}$ & 570.36 & 1989 & 2.06 & 1.47 \\
\hline Valencia & 3.56 & 12.00 & 1945 & 0.55 & 1.82 & 1989 & 340.00 & 582.13 & 1955 & 1.90 & 1.47 \\
\hline Librilla & 2.95 & 12.05 & 1942 & 0.58 & 1.83 & 1948 & 346.00 & 617.43 & 1975 & 1.63 & 1.48 \\
\hline Murcia & 2.66 & 11.96 & 1951 & 0.53 & 1.82 & 1972 & 266.00 & 546.83 & 1977 & 1.91 & 1.46 \\
\hline Orihuela & 4.48 & 11.76 & 1951 & 0.58 & 1.80 & 1946 & 244.00 & 439.25 & 1951 & 1.55 & 1.43 \\
\hline Pinoso & 2.49 & 11.95 & 1951 & 0.52 & 1.82 & 1951 & 345.00 & 535.06 & 1976 & 1.80 & 1.46 \\
\hline
\end{tabular}

$436 \quad *$ : homogeneity rejected

437

438 
Table 3. Values obtained at the Mann-Kendall test

\begin{tabular}{|c|c|c|c|c|c|c|c|}
\hline & & \multicolumn{6}{|c|}{ Station } \\
\hline & & Alicante & Valencia & Librilla & Murcia & Orihuela & Pinoso \\
\hline \multirow{2}{*}{$\begin{array}{l}\text { Average } \\
\text { precipitation }\end{array}$} & $T$ & -0.61 & \multirow{2}{*}{ No trends } & -0.33 & -0.41 & -0.47 & -0.49 \\
\hline & $\mathrm{Zs}$ & -6.05 & & -3.44 & -3.92 & -3.98 & -4.64 \\
\hline \multirow{2}{*}{$D P-40$} & $T$ & -0.64 & 0.45 & -0.73 & -0.38 & -0.56 & -0.81 \\
\hline & Zs & -6.36 & 4.55 & -7.62 & -3.68 & -4.73 & -7.80 \\
\hline \multirow{2}{*}{ DP-20 } & $T$ & -0.55 & 0.50 & -0.11 & -0.48 & -0.72 & -0.66 \\
\hline & $\mathrm{Zs}$ & -5.50 & 5.05 & -1.09 & -4.66 & -6.11 & -6.29 \\
\hline \multirow{2}{*}{$D P-1$} & $T$ & -0.63 & 0.21 & -0.53 & -0.38 & 0.46 & 0.87 \\
\hline & Zs & -6.23 & 2.09 & -5.44 & -3.67 & 3.86 & 8.29 \\
\hline \multirow{2}{*}{$W-P e$} & $T$ & 0.22 & 0.81 & -0.20 & 0.72 & 0.79 & 0.41 \\
\hline & $\mathrm{Zs}$ & 2.18 & 8.11 & -2.10 & 6.93 & 6.63 & 3.93 \\
\hline \multirow{2}{*}{$D-P e$} & $T$ & 0.55 & \multirow{2}{*}{ No trends } & 0.63 & -0.83 & -0.46 & -0.98 \\
\hline & $\mathrm{Zs}$ & 5.47 & & 6.52 & -8.05 & -3.89 & -9.36 \\
\hline \multirow{2}{*}{$T P-w$} & $T$ & \multirow{2}{*}{ No trends } & 0.77 & 0.52 & 0.63 & 0.34 & \multirow{2}{*}{ No trends } \\
\hline & $\mathrm{Zs}$ & & 7.88 & 5.48 & 6.24 & 2.93 & \\
\hline \multirow{2}{*}{$T P-s p$} & $T$ & -0.58 & 0.34 & -0.79 & -0.75 & -0.59 & -0.67 \\
\hline & $\mathrm{Zs}$ & -5.82 & 3.48 & -8.21 & -7.39 & -5.03 & -6.57 \\
\hline \multirow{2}{*}{$T P-s u$} & $T$ & 0.32 & 0.36 & 0.29 & 0.45 & -0.36 & 0.63 \\
\hline & $\mathrm{Zs}$ & 3.23 & 3.71 & 2.99 & 4.46 & -3.04 & 6.21 \\
\hline \multirow{2}{*}{$T P-a u$} & $T$ & -0.58 & -0.49 & -0.68 & -0.74 & -0.50 & -0.66 \\
\hline & $\mathrm{Zs}$ & -5.79 & -5.05 & -7.08 & -7.35 & -4.32 & -6.44 \\
\hline
\end{tabular}

